\title{
GESTÃO DAS COLEÇÕES ARQUEOLÓGICAS DA CASA DA MEMÓRIA INSTITUTO DO ECOMUSEU SÍTIO DO FÍSICO, EM SÃO LUÍS
}

Arkley Marques Bandeira ${ }^{1}$

\begin{abstract}
RESUMO
Este trabalho aborda os resultados obtidos no projeto Curadoria Preventiva das coleções arqueológicas existentes no Instituto do Ecomuseu do Sítio do Físico - São Luís - MA: documentação, informatização e socialização do conhecimento, financiado pela Fundação de Amparo à Pesquisa e ao Desenvolvimento Científico e Tecnológico do Maranhão e desenvolvido entre 2013 e 2015, no âmbito da Casa da Memória da referida Instituição. Os procedimentos consistiram na organização, revisão e atualização de toda a documentação das coleções arqueológicas, manuseio das peças para limpeza e acondicionamento adequado, e ênfase especial na criação de um sistema para o armazenamento e divulgação das coleções, que tiveram aplicabilidade direta na modernização das atividades de rotina das coleções arqueológicas.
\end{abstract}

PALAVRAS-CHAVE: acervo, cultura material, arqueologia, curadoria, documentação.

\section{ABSTRACT}

This paper deals with the results obtained in the Preventive Curation project of the archaeological collections existing in the Institute of the Ecomuseum do Sítio do Físico - São Luís - MA: documentation, computerization and socialization of knowledge, financed by the Foundation for Support to Research and Scientific and Technological Development of Maranhão and developed between 2013 and 2015, within the framework of the House of Memory of the said Institution. The procedures consisted in the organization, revision and updating of all archaeological collections documentation, handling of the pieces for cleaning and adequate packaging, and special emphasis on the creation of a system for the storage and dissemination of collections, which had direct applicability in the modernization of Activities of archaeological collections.

KEYWORDS: collection, material culture, archeology, curatorship, documentation.

\section{RESUMEN}

Este trabajo aborda los resultados del proyecto Curadoria Preventiva de las colecções arqueologícas actualmente existentes en el Instituto de Ecomuseo del Sitio del Físico - São Luís - MA: documentación, información y socialización del conocimiento, financiado por la Fundación de Amparo para la Investigación y el Desarrollo Científico y Tecnológico Maranhão y desarrollada entre el 2013 y el 2015, no âmbito de la Casa de la Memoria de la Institución. El procedimiento consistió en la organización, la revisión y la actualización de toda la documentación de las colecciones arqueológicas, la elaboración de las piezas para la limpieza y el acondicionamiento de los recursos, la creación de un sistema para el

${ }^{1}$ E-mail: arkleymbandeira@gmail.com. ORCID Id: 0000-0002-0410-1082

\begin{tabular}{|l|l|l|l|l|l|l|}
\hline (C) Rev. Arqueologia Pública & Campinas, SP & v.11 & n.2 & p. 138 & Novembro/2017 & ISSN 2237-8294 \\
\hline
\end{tabular} 
almacenamiento y la divulgación de las colecciones, que se aplican directamente a la modernización de las Actividades de rutina de las colecciones arqueológicas.

PALABRAS CLAVE: acervo, cultura material, arqueología, curaduría, documentación.

\section{INTRODUÇÃO}

O presente artigo sintetiza os resultados alcançados no projeto de Curadoria Preventiva das coleções arqueológicas existentes no Instituto do Ecomuseu do Sítio do Físico - São Luís - MA: documentação, informatização e socialização do conhecimento², que consolidou, nesta instituição, o gerenciamento do acervo arqueológico depositado na Casa da Memória.

A implantação do projeto teve implicações diretas na dinamização e ampliação da capacidade de organização e registro das coleções arqueológicas sob a responsabilidade da casa, contribuindo para preservação, proteção, salvaguarda e extroversão desse importante legado cultural maranhense.

O acervo do Ecomuseu Sítio do Físico é composto por coleções arqueológicas oriundas de pesquisas científicas e doações de materiais arqueológicos provenientes de distintas regiões do Maranhão. Para tratar adequadamente as coleções sob a sua guarda, o Instituto do Ecomuseu do Sítio do Físico criou a Casa da Memória, constituída por um laboratório de pesquisa e uma reserva técnica para acondicionamento e armazenamento do acervo ${ }^{3}$.

Após a consolidação da Reserva Técnica de Arqueologia para guarda das coleções arqueológicas, o Instituto do Patrimônio Histórico e Artístico Nacional - Superintendência do Maranhão solicitou oficialmente ao Ecomuseu que recebesse coleções arqueológicas

\footnotetext{
${ }^{2}$ Este trabalho só foi possível devido ao auxílio concedido pela Fundação de Amparo à Pesquisa e ao Desenvolvimento Científico e Tecnológico do Maranhão - FAPEMA. Solicitação CBIOMA03069/13 - Modalidade CBIOMA - Apoio ao Programa Acervos do Maranhão Coleções Biológicas e Arqueológicas. Edital FAPEMA № 026/2013 CBIOMA - Vigência: 03/12/2013 a 03/12/2015.

${ }^{3} \mathrm{O}$ Ecomuseu Sítio do Físico surgiu da iniciativa dos colaboradores e parceiros do Sr. Fernando Mendonça e da Sra. Nery Mendonça, proprietários da área onde se encontram as ruínas do Sítio do Físico e o Sambaqui do Bacanga, que atuando na perspectiva do voluntariado social, desenvolvem ações sociais e ambientais sem fins lucrativos para proteção e conhecimento desses bens culturais. Visando à formalização dessas ações foi criada tal associação, em 24 de junho de 2006, denominada Instituto do Ecomuseu Sítio do Físico - IESF, substituindo a antiga Associação dos Amigos do Ecomuseu Sítio do Físico - AAESF. Estatutariamente, a instituição é composta por um corpo diretivo, com membros responsáveis por diferentes pastas, cujos representantes são eleitos por voto direto dos associados. Além de promover a defesa do meio ambiente por meio de ações solidárias e com uma rede de parceiros diversificada, a entidade tem forte atuação comunitária, principalmente na região Itaqui-Bacanga, e nos bairros do Coroadinho e Vila dos Frades, difundido sua missão, uma das áreas mais carentes de São Luís - Maranhão.
}

\begin{tabular}{|l|l|l|l|l|l|l|}
\hline (C) Rev. Arqueologia Pública & Campinas, SP & v.11 & n.2 & p. 139 & Novembro/2017 & ISSN 2237-8294 \\
\hline
\end{tabular}




\section{ARTIGO}

\section{Revista de Arqueologia Pública}

oriundas de projetos de pesquisa vinculados ao licenciamento ambiental no Estado do Maranhão, mediante a emissão de endossos institucionais para salvaguarda de materiais arqueológicos. Além disso, a instituição também recebeu como doação as coleções arqueológicas que estavam sob a guarda do IPHAN - MA, que foram formadas a partir das intervenções arquitetônicas na área tombada do Centro Histórico de São Luís.

Neste artigo apenas a metodologia e os resultados obtidos serão enfocados, principalmente aqueles relacionados à organização das coleções arqueológicas existentes na Casa da Memória, com ênfase na descrição dos procedimentos de manuseio dos materiais arqueológicos e acondicionamento.

\section{PROCEDIMENTOS METODOLÓGICOS ADOTADOS NO PROJETO}

No Projeto em questão, a curadoria preventiva organizou, documentou e registrou as coleções arqueológicas existentes na Casa da Memória do Instituto do Ecomuseu do Sítio do Físico. Para tanto, foi proposta uma metodologia para melhoria da rotina de sistematização e gestão interna sobre as informações das coleções, que também serviu como ferramenta de extroversão do conhecimento.

Tais procedimentos foram realizados após o treinamento da equipe técnica em cursos de curta duração ministrados por profissionais de notório conhecimento em sua área de atuação, que se relacionaram aos distintos elementos que constituem o acervo arqueológico da Instituição.

Nesse contexto, foram alcançados padrões mínimos, que incluíram o uso de vocabulários controlados, arquivamento hierarquizado, normatizações pré-estabelecidas e testes de validade dos procedimentos adotados. De posse destas informações, o passo seguinte consistiu na informatização e registro do acervo em banco de dados, com a digitalização e armazenamento da documentação relacionada às coleções.

A reserva técnica da Casa da Memória do Instituto do Ecomuseu do Sítio do Físico não se difere de outras instituições semelhantes: possui uma série de bancos de dados, mantendo informações atualizadas acerca de todas coleções sob a sua guarda, seja temporária, ou permanente. Todavia, esses bancos de dados não faziam parte de um sistema integrado e não se organizavam relacionalmente. Isso se deu pelo modelo do banco de dados atual ser pautado em premissas já ultrapassadas, a exemplo de "usuário único"; "uma tarefa por vez"; "banco de dados local" etc. 
Diante dessa situação, foi proposta uma metodologia que, para além da melhoria na sistematização e gestão interna das coleções, pudesse servir como ferramenta de extroversão do conhecimento, seguindo tabelas de temporalidade acerca do acesso de cada nível de informação. Após esse procedimento, foi possível usufruir dos dados brutos, documentos gerados, informações sobre os materiais coletados, localização das peças, dentre outros aspectos.

Além disso, foram buscadas as ferramentas da Tecnologia da Informação, a exemplo do Cloud Computing, tratando-se de um sistema de armazenamento de dados acessível de qualquer local do mundo, podendo ser utilizado por múltiplos usuários, desempenhando várias atividades simultâneas - pesquisa, inserção, atualização, sem ônus para nenhuma das partes.

Com o intuito de aumentar a segurança das ações relacionadas à movimentação física das peças e/ou conjuntos de peças dentro da Reserva Técnica, utilizou-se de códigos alfanuméricos como facilitador de acesso à informação. A esse respeito, as coleções receberam etiquetas de identificação, que por sua vez foram registradas nas caixas arquivos e nas prateleiras das estantes onde as coleções arqueológicas ficam depositadas.

Após os procedimentos de documentação e informatização, foi feito novo acondicionamento das coleções arqueológicas, seguindo os princípios da conservação preventiva, com as atividades preliminares como a limpeza e armazenamento na reserva técnica ${ }^{4}$.

A metodologia foi estruturada nas seguintes etapas, principiadas pelo levantamento das coleções arqueológicas, e finalizando com o registro das próprias em um sistema de informação:

\section{ETAPA 1 - LEVANTAMENTO DOCUMENTAL DAS COLEÇÕES ARQUEOLÓGICAS}

a. O passo inicial consistiu em realizar um diagnóstico de todas as coleções arqueológicas depositadas no Instituto do Ecomuseu do Sítio do Físico (conferência, estado de conservação e forma de acondicionamento);

b. em seguida, realizou-se o levantamento de toda a documentação concernente às coleções arqueológicas, tendo referência os relatórios técnicos e de pesquisa que geraram

${ }^{4}$ A esse respeito, Braga (2001) indicou que o "acondicionamento" se refere ao trabalho de acomodação dos artefatos em embalagens ou sistemas que forneçam estabilidade física e química; ao passo que "armazenamento" é a guarda e organização desses objetos nos mobiliários.

\begin{tabular}{|l|l|l|l|l|l|l|}
\hline ๑) Rev. Arqueologia Pública & Campinas, SP & v.11 & n.2 & p. 141 & Novembro/2017 & ISSN 2237-8294
\end{tabular} 
a coleção, cadernos de campo, mapas, cartas, ofícios, documentos de endossos, banco de dados, fotos, croquis, desenhos, filmagens etc.

\section{ETAPA 2 - LOCALIZAÇÃO E MANUSEIO DAS COLEÇÕES ARQUEOLÓGICAS}

a. Nesta fase as coleções arqueológicas foram localizadas e triadas. Além disso, foi feita a associação das próprias com a documentação correspondente levantada na Etapa 1;

b. Na triagem, as coleções arqueológicas foram separadas pela natureza do vestígio arqueológico. O acervo pré-histórico foi categorizado em lítico, cerâmico, ósseo, dente, malacológico, vegetal, sedimentos etc.; já o histórico, em louça, metal, vidro, material construtivo, osso, dente, malacológico etc.

c. Foi realizada limpeza a seco dos vestígios inorgânicos.

\section{ETAPA 3 - DOCUMENTAÇÃO E INFORMATIZAÇÃO DAS COLEÇÕES ARQUEOLÓGICAS}

a. Com base na visualização das coleções obtidas nas etapas anteriores, criou-se um sistema de documentação com um banco de dados para registro e informatização de todo o acervo;

b. Foram levantadas as rotinas e processos referentes às atividades gerais da reserva técnica;

c. Foi desenhado um banco de dados relacional baseado nos outros dispositivos para o registro das coleções já existentes;

d. Foi criada uma versão inicial do Sistema de Gerenciamento;

e. Foi realizada a migração das informações dos bancos de dados antigos para a nova plataforma;

f. Foram realizadas a revisão dos novos dados e a conferência com os antigos bancos de dados;

g. Novas adaptações e redefinições foram realizadas, com vistas a melhorar o Sistema de Gerenciamento;

h. Foi revisada e adequada a documentação de registro das coleções arqueológicas;

i. Digitalizou-se toda a documentação de registro das coleções arqueológicas;

\begin{tabular}{|l|l|l|l|l|l|l}
\hline (C) Rev. Arqueologia Pública & Campinas, SP & v.11 & n.2 & p. 142 & Novembro/2017 & ISSN 2237-8294
\end{tabular}


j. Foram criados códigos identificadores para cada coleção arqueológica, peça individual e local de guarda.

\section{ETAPA 4 - ACONDICIONAMENTO E ARMAZENAMENTO DAS COLEÇÕES ARQUEOLÓGICAS}

a. Todo o material foi acondicionado em embalagens adequadas de acordo com a natureza do vestígio (histórico ou pré-histórico; orgânico ou inorgânico);

b. O armazenamento das coleções arqueológicas foi devidamente documentado, registrado, catalogado e informatizado no mobiliário.

\section{ORGANIZAÇÃO DAS COLEÇÕES ARQUEOLÓGICAS E A INTERFACE DO GERENCIAMENTO DO ACERVO}

O tratamento do acervo da Casa da Memória foi composto por algumas ações que foram fundamentais para diagnosticar as condições das coleções arqueológicas. Para tanto, foram buscadas informações iniciais relacionadas às referidas coleções:

\section{$\checkmark$ Procedência}

$\checkmark$ Forma como as coleções foram geradas

$\checkmark$ Modalidade do projeto de pesquisa que gerou a coleção

$\checkmark$ Responsável técnico pela formação das coleções

$\checkmark$ Status do conhecimento sobre as coleções

$\checkmark$ Disponibilidade de documentação associada às coleções

Após esse procedimento, as coleções arqueológicas foram manuseadas, considerando os seguintes aspectos:

$\checkmark$ Forma de acondicionamento

$\checkmark$ Estado de conservação

$\checkmark$ Quantificação das peças

Em um primeiro momento, foram priorizadas as coleções que não haviam passado por qualquer processo curatorial, ou seja, as que estavam depositadas da mesma forma que chegaram das escavações arqueológicas, com as fichas e embalagens originais. Nestes casos, estas foram substituídas por novo etiquetamento e acondicionamento dos 


\section{Revista de Arqueologia Pública}

materiais em sacos plásticos zip-loc, respeitando todas as informações de proveniência advindas do campo.

Independentemente da tipologia das coleções arqueológicas trabalhadas neste Projeto, a cadeia operatória das atividades de curadoria e documentação seguiram as seguintes etapas:

O primeiro passo consistiu em separar as coleções arqueológicas de acordo com a forma que elas foram geradas e o processo de pesquisa correspondente. Posteriormente, foi feita a revisão das fichas de identificação das coleções. Quando as fichas apresentaram sujeiras, rasgos, rabiscos, foram substituídas por uma nova ficha, mantendo as mesmas informações anteriores. Caso algum campo de informação estivesse em branco e a documentação arqueológica permitisse o seu preenchimento, este foi realizado.

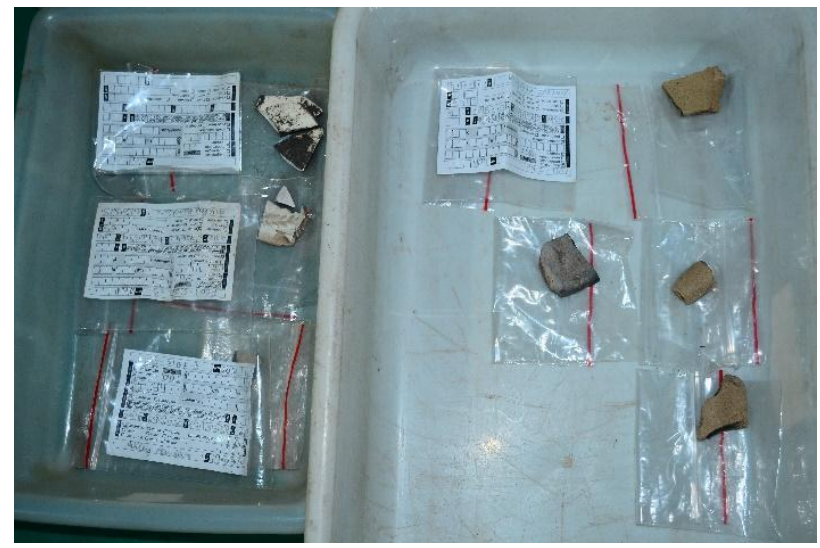

Figura 1 - Conferência do material arqueológico em relação à Ficha de proveniência. Fonte: Arkley Bandeira, 2015.

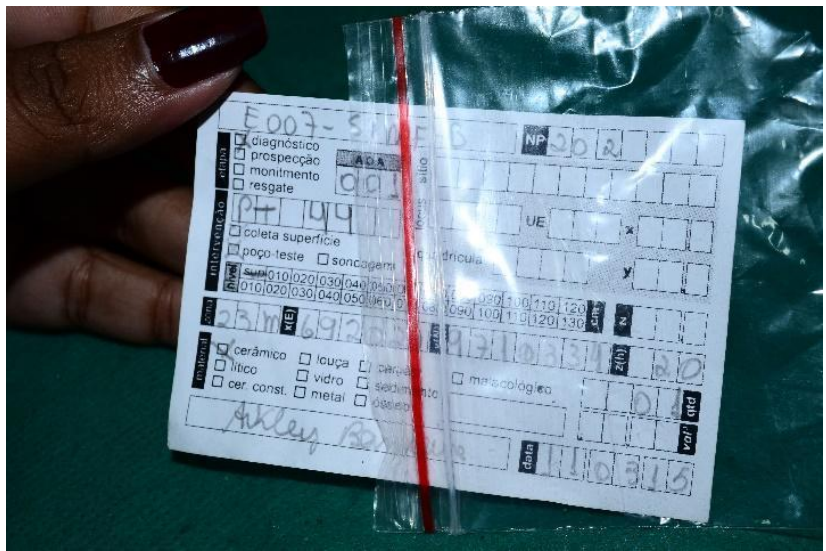

Figura 2 - Substituição das fichas de proveniência e embalagens. Fonte: Arkley Bandeira, 2015. 
Revista de Arqueologia Pública

ARTIGO

Em seguida, o material foi higienizado, priorizando a limpeza a seco, com o uso de pincéis de cerdas macias. Quando não foi possível a limpeza a seco, o material foi lavado em água corrente, com o uso de uma escova com cerdas macias.

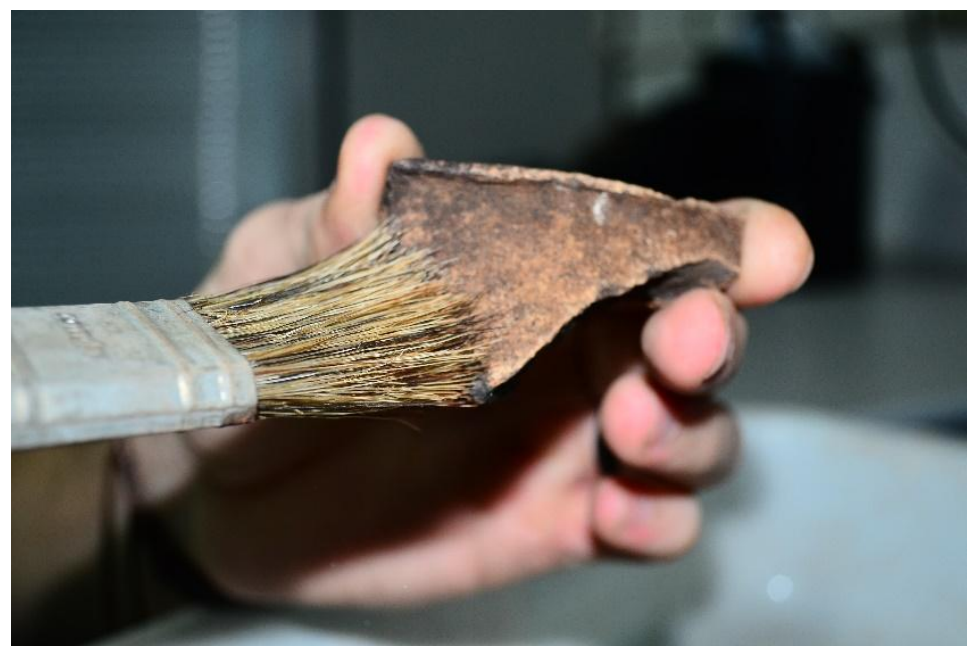

Figura 3 - Limpeza a seco do material arqueológico após a substituição das fichas de proveniência. Fonte: Arkley Bandeira, 2015.

Após a limpeza, o material arqueológico foi novamente contabilizado e os quantitativos foram comparados com a primeira contagem realizada ainda em campo. Nessa fase, foi feita a seleção do material arqueológico, para fins de registro, análise, exposição etc.

O passo seguinte consistiu em realizar a documentação e o registro das coleções arqueológicas no banco de dados, que por sua vez alimentou o sistema de gerenciamento do acervo arqueológico da Instituição. 


\section{ARTIGO}

\section{Revista de Arqueologia Pública}
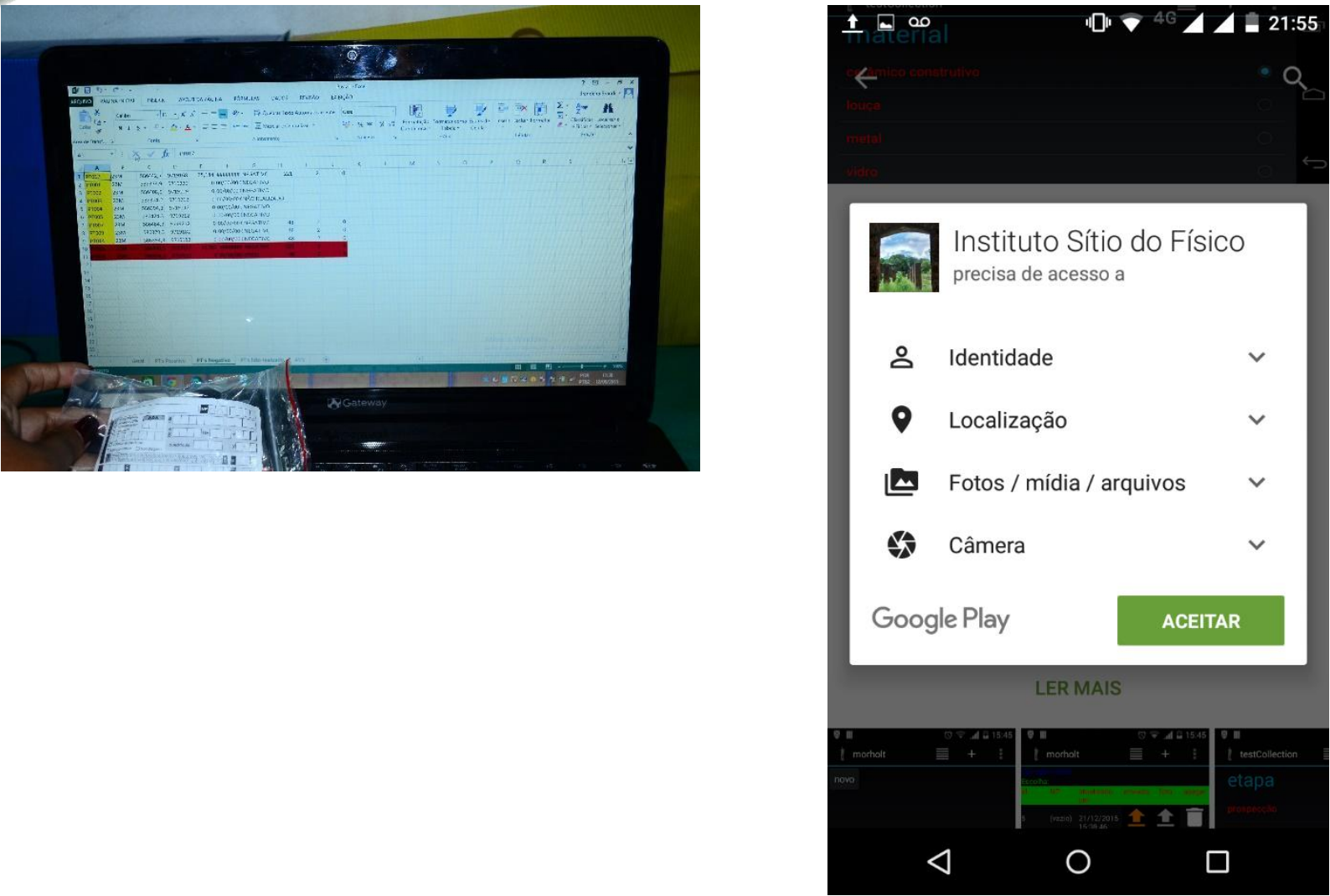

Figura 4 - Preenchimento do banco de dados com as informações sobre as coleções arqueológicas. Fonte:

Arkley Bandeira, 2015.
Figura 5 - Preenchimento do sistema de gerenciamento via mobile com as informações sobre as coleções arqueológicas. Fonte: Arkley Bandeira, 2015.

A catalogação foi feita contabilizando todos os elementos que formam as coleções arqueológicas, de acordo com a natureza de cada objeto, além de informações de proveniência, a exemplo da Identificação, Etapa, Data, Área, Sítio, Material, Quantidade, Número Provisório, Origem, Nível, Local, Coordenadas Geográficas, Coletor, Foto, Observações, Localização na Reserva Técnica, Desmembrado, Número de Proveniência, origem, dentre outras.

Após a alimentação do Banco de Dados, o Material foi fotografado, embalado, lacrado e depositado em caixas arquivos ou engradados identificados.

A síntese dos dados existentes no sistema de gerenciamento pode ser acessada por filtros, sendo apresentada em quadros informativos que documentam em tempo real as características de cada coleção arqueológica. Como exemplo, segue o Quadro 1, com o resumo da Coleção Arqueológica do PBA de Arqueologia da Via Expressa e do resgate do Sítio Arqueológico Vinhais Velho, em São Luís - MA.

\begin{tabular}{|l|l|l|l|l|l|l|}
\hline (C) Rev. Arqueologia Pública & Campinas, SP & v.11 & n.2 & p. 146 & Novembro/2017 & ISSN 2237-8294
\end{tabular}


Revista de Arqueologia Pública

\section{Quadro 1 - Resumo da Coleção Vinhais Velho - Via Expressa}

\begin{tabular}{|l|c|c|c|c|}
\hline \multicolumn{5}{|c|}{ Total de Fragmentos Coletados por Etapa na Via Expressa } \\
\hline \multicolumn{1}{|c|}{ Material } & Prospecção & Resgate & Peneiramento & Total \\
\hline Ce râmica & 11 & 7618 & 1973 & $\mathbf{9 6 0 2}$ \\
\hline Lítico & 0 & 62 & 55 & $\mathbf{1 1 7}$ \\
\hline Ce râmica Construtiva & 0 & 21 & 1 & $\mathbf{2 2}$ \\
\hline Louça & 162 & 173 & 40 & $\mathbf{3 7 5}$ \\
\hline Metal & 0 & 2 & 4 & $\mathbf{6}$ \\
\hline Vidro & 7 & 17 & 4 & $\mathbf{2 8}$ \\
\hline Osso & 0 & 145 & 17 & $\mathbf{1 6 2}$ \\
\hline Malacológico & 0 & 682 & 33 & $\mathbf{7 1 5}$ \\
\hline Laterita & 0 & 27 & 1 & $\mathbf{2 8}$ \\
\hline Argila & 0 & 0 & 2 & $\mathbf{2}$ \\
\hline Outros & 0 & 1 & 0 & $\mathbf{1}$ \\
\hline N/Identificado & 0 & 1 & 0 & $\mathbf{1}$ \\
\hline \multicolumn{1}{|c|}{ Total } & $\mathbf{1 8 0}$ & $\mathbf{8 7 4 9}$ & $\mathbf{2 1 3 0}$ & $\mathbf{1 1 0 5 9}$ \\
\hline
\end{tabular}

\begin{tabular}{|l|c|c|c|c|}
\hline \multicolumn{5}{|c|}{ Total de Amostras Coletadas por Etapa na Via Expressa } \\
\hline \multicolumn{1}{|c|}{ Amostra } & Prospecção & Resgate & Peneiramento & Total \\
\hline Amostra Vegetal & 0 & 4 & 11 & $\mathbf{1 5}$ \\
\hline Carvão & 0 & 33 & 0 & $\mathbf{3 3}$ \\
\hline Sedime nto & 0 & 12 & 0 & $\mathbf{1 2}$ \\
\hline \multicolumn{1}{|c|}{ Total } & $\mathbf{0}$ & $\mathbf{4 9}$ & $\mathbf{1 1}$ & $\mathbf{6 0}$ \\
\hline
\end{tabular}

\begin{tabular}{|c|c|c|c|c|}
\hline \multicolumn{7}{|c|}{ Estruturas coletadas por Etapa na Via Expressa } \\
\hline Estrutura & Prospecção & Resgate & Peneiramento & Total \\
\hline Estrutura de Combustão & 0 & 1 & 0 & 1
\end{tabular}

Os materiais arqueológicos mais diagnósticos ou que demandaram cuidados especiais no seu acondicionamento foram embalados em plástico bolha e acondicionados individualmente em caixas de isopor. Com as coleções arqueológicas devidamente higienizadas, catalogadas e armazenadas foi feita uma triagem das peças arqueológicas mais diagnósticas para realização de registro fotográfico em estúdio.

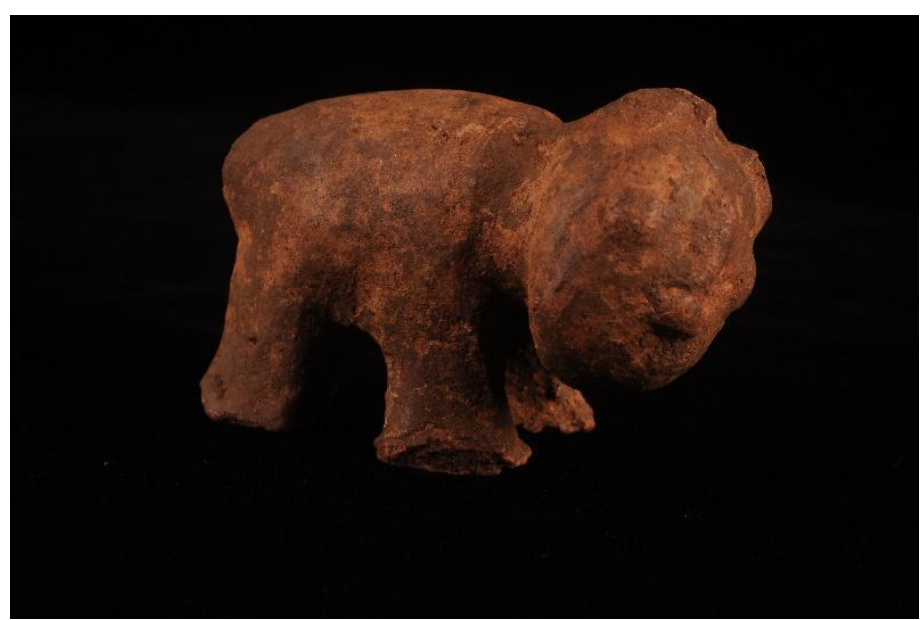

Figura 6 - Escultura zoomorfa em cerâmica representando um felino coletada no Sítio Vinhais Velho, em São Luís - MA. Fonte: Edgar Rocha, 2013. 


\section{ARTIGO}

\section{Revista de Arqueologia Pública}

Após o registro fotográfico, o material foi acondicionado em novas embalagens de sacos plásticos zip-loc, com a respectiva ficha de proveniência e depositados em caixas arquivo polionda, com a respectiva identificação da coleção arqueológica. Por sua vez, as caixas arquivos foram armazenadas em prateleiras de aço, com a respectiva identificação.

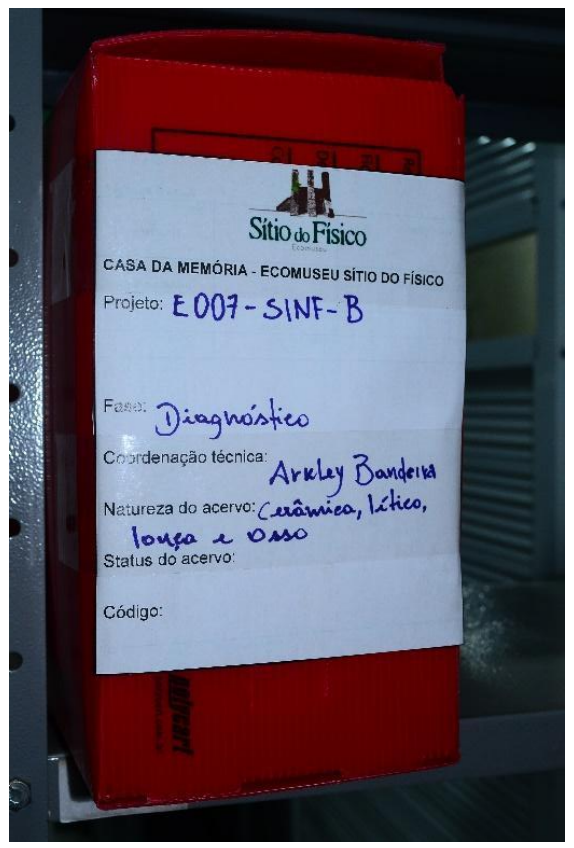

Figura 7 - Armazenamento das caixas arquivos nas prateleiras e armários de aço. Fonte: Arkley Bandeira, 2015.

Em relação às coleções doadas por outras instituições, os procedimentos foram diferenciados, no que concernem à substituição das embalagens e à padronização das informações das fichas de proveniência, visto que, na maioria dos acervos advindos de outras instituições, o acondicionamento não era adequado, e as informações eram fragmentadas, incompletas ou inexistentes.

Nesses casos, foram feitas novas fichas de proveniência, e todas as embalagens foram substituídas, conforme a padronização de rotina demonstrada anteriormente.

Além da organização de toda a documentação existente no Instituto do Ecomuseu Sítio do Físico, o Projeto também criou um sistema de informação e gerenciamento das coleções arqueológicas existentes na reserva técnica da instituição. 


\section{ARTIGO}

\section{Revista de Arqueologia Pública}

O sistema desenvolvido durante esse período foi de extrema importância para a pesquisa arqueológica, pois a partir dele foi possível tornar o acesso à informação dinâmico e igualitário. Ao longo do desenvolvimento do sistema, foi criado um guia de utilização, com o objetivo de explicar a funcionalidade do próprio. Ressalta-se, contudo, que o Sistema ainda não está disponível ao grande público, visto que se encontra na fase de revisões e testes finais.

\section{CONSIDERAÇÕES FINAIS}

O acervo da Casa da Memória do Instituto do Ecomuseu do Sítio do Físico é formado por coleções de natureza arqueológica oriundas de pesquisas científicas e doações de materiais representativos do patrimônio cultural maranhense, compostas de materiais orgânicos, a exemplo de ossos, malacológicos, carvão e sementes, fibras; e inorgânicos, a exemplo de artefatos em rocha, objetos cerâmicos, sedimentos, louças, vidros, materiais construtivos, metais, entre outros.

As primeiras coleções arqueológicas foram incorporadas na instituição resultantes das escavações vinculadas ao projeto de pesquisa Sambaquis do Maranhão, que investigou vários sítios arqueológicos da llha de São Luís, desde 2005. Os dados obtidos em nove anos de pesquisa resultaram em três teses de doutorado e três dissertações de mestrado, defendidos em instituições brasileiras e estrangeiras.

Após a consolidação da Reserva Técnica de Arqueologia para guarda das coleções arqueológicas do Projeto Sambaquis do Maranhão, o IPHAN - Superintendência do Maranhão solicitou oficialmente ao Instituto do Ecomuseu do Sítio do Físico que recebesse outras coleções arqueológicas oriundas de projetos de pesquisa de arqueologia vinculadas ao licenciamento ambiental.

Com o projeto em questão já foi possível organizar as coleções oriundas de cerca de 130 projetos de pesquisa, mesmo aqueles que não geraram acervos arqueológicos, sendo que um dos principais resultados alcançados na implantação da Curadoria Preventiva das coleções arqueológicas existentes no Instituto do Ecomuseu do Sítio do Físico - São Luís MA: documentação, informatização e socialização do conhecimento foi a organização e preparação do acervo da instituição para o público consulente.

Se anteriormente o acesso e estudo das coleções arqueológicas eram dificultados pelo simples fato do desconhecimento sobre a natureza do acervo, principalmente em 


\section{ARTIGO}

\section{Revista de Arqueologia Pública}

relação às coleções doadas por outras instituições, a fase atual de conhecimento, mesmo após a recém conclusão deste Projeto, já permite informar ao público o que ele deve encontrar no acesso aos materiais arqueológicos.

Outro aspecto notoriamente alcançado, inclusive nas primeiras etapas deste Projeto, referiu-se ao alcance de padrões mínimos relacionados à conservação das coleções arqueológicas, principalmente, concernentes à higienização, acondicionamento, documentação e informatização de todo o acervo arqueológico.

Se antes da implantação deste Projeto - entre novembro e dezembro de 2013 menos da metade das coleções arqueológicas da Casa da Memória estava documentada e curada, com o término da iniciativa, $100 \%$ do acervo arqueológico, inclusive as coleções doadas por outras instituições, foram adequadamente trabalhadas.

A esse respeito, um dos principais desafios deste Projeto foi adequar em uma mesma linguagem as coleções arqueológicas geradas por distintas atividades. Somam-se a isto a falta de documentação sobre as pesquisas que geraram as coleções do IPHAN e da Fábrica Santa Amélia e o péssimo estado de acondicionamento das próprias. Além disso, outro ponto que dificultou o processo de padronização das coleções foi o volume de materiais da Coleção Sambaquis do Maranhão, que totaliza quase 60 mil exemplares.

O sistema de informatização e gerenciamento foi um diferencial nesse processo e, futuramente, poderá ser distribuído para outras instituições, inclusive, partilhando a mesma tecnologia para gestão de coleções e acervos de acesso livre, podendo ser implantada, modificada e melhorada em qualquer reserva técnica, museu e instituição.

Com a implantação deste Projeto, a salvaguarda, a preservação e a socialização das coleções arqueológicas consolidaram a importância regional da Casa da Memória do Instituto Sítio do Físico, inaugurando um novo momento na instituição. Este se deu com a adequação ao tempo presente, quando redes de colaboração e a força dos aplicativos e informatização dos processos dão a tônica na gestão dos acervos e coleções, resultando em parâmetros mais consolidados na produção do conhecimento científico. 


\section{REFERÊNCIAS BIBLIOGRÁFICAS}

AFONSO, Marisa Coutinho et al. Organização e gerenciamento do acervo arqueológico préhistórico brasileiro no MAE/USP: o projeto CAB. Revista do Museu de Arqueologia e Etnologia, São Paulo, vol. 9, 1999.

BANDEIRA, Arkley Marques. Relatório técnico final do projeto de Curadoria Preventiva das coleções arqueológicas existentes no Instituto do Ecomuseu do Sítio do Físico - São Luís - MA: documentação, informatização e socialização do conhecimento. FAPEMA. São Luís, 2015.

BRAGA, Gedley. B. A Conservação das coleções do MAE/USP. In: Brasil 50 mil anos: uma viagem ao passado pré-colonial. EDUSP/Museu de Arqueologia e Etnologia da USP. São Paulo, 2001.

BOTTALLO, Marilucia. O papel da documentação museológica nos processos de salvaguarda patrimonial: a montagem da exposição temporária. In: Brasil $\mathbf{5 0}$ mil anos: uma viagem ao passado pré-colonial. MAE - USP. São Paulo, 2001.

BRUNO, Maria Cristina Oliveira. O Museu do Instituto de pré-História: um museu a serviço da pesquisa científica. Dissertação de Mestrado, Faculdade de Filosofia, Letras e Ciências Humanas da Universidade de São Paulo, São Paulo, 1984.

Musealização da Arqueologia: um estudo de modelos para o Projeto Paranapanema. Tese de Doutorado. Faculdade de Filosofia, Letras e Ciências Humanas da Universidade de São Paulo, São Paulo, 1995.

A luta pela Perseguição ao Abandono. Tese de Livre Docência, Museu de Arqueologia e Etnologia da Universidade de São Paulo, São Paulo, 2000.

CERAVOLO, Suely Moraes; TÁLAMO, M. F. G. M. Tratamento e organização de informações documentárias em museus. Revista do Museu de Arqueologia e Etnologia, São Paulo, v. 10, 2000. 
Revista de Arqueologia Pública

MORAES, Camila Azevedo de. Museus e os descaminhos do patrimônio arqueológico: (des) caminhos da prática brasileira. Tese de doutorado apresentada ao Programa de PósGraduação em Museologia. Lisboa: Humanidades e Tecnologias, 2010.

Patrimônio Arqueológico Paulista: proposições e provocações museológicas. Tese de Doutorado. Museu de Arqueologia e Etnologia da Universidade de São Paulo, São Paulo, 2011.

SALADINO, Alejandra et al. A César o que é de César: o patrimônio arqueológico nas organizações formais do Brasil. Revista de Arqueologia Pública. São Paulo: v. 7, n. 2, 2013. 